\title{
Los medios de comunicación de masas, contra la dictadura somocista
}

\section{The mass media, against the Somoza dictatorship}

\begin{abstract}
Belén Amador Rodríguez
Licenciada en Comunicación Social, con maestría en Estudios Latinoamericanos. Cursa estudios de doctorado en Comunicación en la Universidad de Sevilla (España). Docente e investigadora en la Universidad Técnica Luis Vargas Torres, de Esmeraldas. Su línea de investigación es Publicidad y Relaciones Públicas. Investiga el tema de la propaganda sandinista en Nicaragua.
\end{abstract}

Correo: amarod1981@hotmail.com

\section{Pablo Tatés Anangonó}

Licenciado en Artes Escénicas por la Universidad Central del Ecuador, con maestría en Estudios de la Cultura, mención Comunicación, por la Universidad Andina Simón Bolívar-Sede Ecuador. Docente en la Universidad Central del Ecuador. Su línea de investigación es Comunicación y Cultura, y su trabajo artístico se centra en los derechos del pueblo afrodescendiente en Ecuador.

Correo: pablotatesnangono@gmail.com

\section{Resumen}

En este trabajo analizamos la influencia de los medios de comunicación de masas en el derrocamiento de la dictadura en Nicaragua. Tras dos años de lucha armada, la organización guerrillera Frente Sandinista de Liberación Nacional (FSLN) se hizo con el poder y puso fin a la dinastía de los Somoza en 1979. A través de la revisión bibliográfica pondremos especial atención en los nexos existentes entre los acontecimientos políticos, militares y comunicativos.

Palabras clave: medios de comunicación de masas, dictadura en Nicaragua, lucha armada, Frente Sandinista de Liberación Nacional, dinastía de los Somoza.

\section{Abstract}

Through this paper we analyze the influence of mass media in the overthrow of the dictatorship in Nicaragua. After two years of armed conflict, the guerrilla organization "FSLN (Frente Sandinista de Liberación Nacional)" took the power and end to the Somoza dynasty in 1979. Throughout the bibliographic review we will pay special attention to the existing links between political, military and communicative events.

Keywords: mass media, dictatorship in Nicaragua, armed conflict, Sandinista Liberation National Front, Somoza dynasty. 


\section{Introducción}

Hacer historia de los procesos implica hacer historia de las categorías con las que los analizamos y de las palabras con las que los nombramos. Lenta pero irreversiblemente, hemos aprendido que el discurso no es un mero instrumento pasivo en la construcción del sentido que toman los procesos sociales, las estructuras económicas o los conflictos políticos (Martín Barbero, 2003:3). En las sociedades modernas los medios de comunicación, nos referimos a los de masas, sirven para realizar incesantemente el trabajo ideológico crítico de "clasificar el mundo" dentro de los discursos de las ideologías dominantes (Hall, 1981:32). Actúan como sistema de transmisión de mensajes y símbolos para el ciudadano medio y, además de divertir, entretener e informar, inculcan los valores, creencias y códigos de comportamiento para integrarnos en las estructuras institucionales de la sociedad (Chomsky, 1990:21).

En 1961 se creó el Frente Sandinista de Liberación Nacional (FSLN), un movimiento guerrillero fruto de la voluntad de jóvenes radicales disidentes del Partido Socialista de Nicaragua y del Partido Conservador. Los fundadores -entre los que se encontraban Carlos Fonseca Amador, Tomás Borge y Silvio Mayorg- pertenecían a la generación que observó la habilidad de Anastasio Somoza García en instaurar un régimen de carácter patrimonial y en cooptar a los cuadros del Partido Conservador (Martí y Puig, 1997: 21). Un año después del surgimiento del FSLN, el hijo de Anastasio Somoza, Luis Somoza, promulga el Código de Radio y Televisión, bautizado por los periodistas como el 'Código Negro', que daba amplias facultades a la Guardia Nacional para censurar a los periodistas y cerrar los distintos medios de comunicación, tanto escritos como audiovisuales. Este Código se hizo para evitar la propaganda de la lucha armada, política o ideológica contra el somocismo, impulsada por el FSLN. Constituía realmente una ley de excepción en contra del ejercicio periodístico y en contra de la difusión de cualquier ideología que no fuera el liberalismo a ultranza o el conservadurismo tradicional (Amador, 2008:161).

El sistema político, económico y social dominante en cada momento histórico determina tanto la estructura organizativa de los medios de comunicación como el proceso comunicativo que se lleva a cabo en esa sociedad. Desde este punto de vista, en Nicaragua pueden establecerse dos etapas claramente diferenciadas (De Mateo, 1988). La primera comienza en 1933: se configura un sistema de comunicación de masas al servicio de la dictadura somocista. Mientras que la segunda se da a partir de 1972: al entrar en crisis el proyecto hegemónico somocista, se acrecientan las contradicciones sociales y políticas en el interior del sistema, que provocan, cinco años después, una estrategia de alianzas de todas las fuerzas que desean terminar con la dictadura de Somoza (De Mateo, 1988: 81).

Es entonces cuando algunos medios de comunicación institucionales, como el diario La Prensa, participan en este proceso. Además, el FSLN tuvo que ingeniarse sus propios medios de comunicación. Los sandinistas tuvieron que tomar por la vía de las armas distintas radioemisoras para poder hacer llegar su mensaje al pueblo. A mediados de 1978 se pone en marcha la emisora clandestina, Radio Sandino -que cumple una función 
importante en la agitación, organización y preparación combativa de quienes quieren alzarse-, y en el propio frente de guerra nace el cine nacional. Concretamente en el Frente Sur Benjamín Zeledón, la Brigada Cultural Leonel Rugama logró filmar gran cantidad de películas y documentales.

En este trabajo pensaremos la comunicación en su dimensión mediática, es decir, colocaremos la mirada en territorios propicios para reflexionar la racionalidad a la que responden las prácticas discursivas de los medios (Fernández, 2016). Según McLuhan los medios de comunicación de masas han transformado la vida de los hombres y su relación con el entorno, estos tienen el mérito de constituirse en extensiones de nuestra capacidad de conocer, pues "construyen un lenguaje social específico, que hace cambiar nuestras percepciones sobre la sociedad y nuestras relaciones con los demás" (citado en Vera, 1998:71). Basados en esta premisa, vamos a analizar el papel que los medios de comunicación mencionados anteriormente jugaron en el derrocamiento de la dictadura somocista.

\section{Comunicación y poder}

A lo largo de la historia, la comunicación y la información han constituido fuentes fundamentales de poder y contrapoder, de dominación y de cambio social (Castells, 2008). Cuando hablamos de medios de comunicación nos referimos tanto a los de masas como a otras formas de comunicación. Dentro de los primeros se encuentra la prensa, que acompañó a las guerras y revoluciones del siglo XX, que dan un relevo a la radio y al cine, medios que técnicamente nacen a finales del siglo XIX, pero que adquirirán su verdadera fisonomía y dimensión a partir de las primeras décadas del XX (Bordeira, Laguna y Martínez, 1998:348). Y entre los segundos destaca el arte propagandístico, que es aquel en que, durante el proceso de creación o recepción de la obra, ha participado un emisor de propaganda: "El propagandista realiza esta intervención aportando un determinado mensaje ideológico a la obra de arte, la cual puede estar ausente de ideología o bien puede contener una ideología preexistente que ahora se verá alterada" (Bellido, 2018:335).

Es innegable el valor ideológico-político que se le confiere al trabajo de los medios nicaragüenses (mediación) (Molina, 2002), el cual resulta determinante para el derrocamiento de la dictadura somocista. Ante un conflicto, lo inmediato es suponer que son los medios de comunicación los promotores de la relación con los insurrectos, dada la preferencia de la prensa por sucesos dramáticos (Calvo, 2010:1576). La realidad se antoja distinta al observar que la relación con los medios es promovida desde el movimiento, como necesidad para garantizar su supervivencia. Los medios de comunicación actuarían así como constructores del mito revolucionario. Prueba de ello, en el caso de Nicaragua, es la declaración del comandante en jefe del Ejército Popular Sandinista y ministro de Defensa, Humberto Ortega: "ya en esa época teníamos plena conciencia de la necesidad de una radio, de una forma de comunicación con las masas para educarlas para la insurrección" (citado en Harnecker, 1983:14). De hecho, explica que en 1960 los sandinistas tenían una radio "que la habían usado los primeros antisomocistas, que estaba vieja y en ese momento no pudimos echarla a andar" (citado en Harnecker, 1983:14). 
Con la profusión de los medios de comunicación social estos han alcanzado grados importantes de poder entre el público, ya que ejercen su influencia, moldean sus maneras de mirar el mundo, vivir la política, formar la familia, organizar el Estado o construir la sociedad (Calvo, 2010). Periódico, radio, cine y televisión, en los albores de los setenta, se alzaban contra los transmisores de incontables mensajes a las audiencias de todo el mundo en todo momento. Y cada mensaje emitido se destinaba (y destina) a conseguir un objetivo concreto, según sea el interés de su emisor: informar, persuadir, formar... Como constructores de la realidad, los medios guían a las audiencias, bien por la orientación de los mensajes transmitidos, por el grado de concertación de múltiples medios en un mismo objetivo, o por el grado de persuasión y credibilidad que logren entre sus receptores (Calvo, 2010).

\section{La Prensa, determinante en el derrocamiento de la dictadura}

En 1967, el somocismo promulgó un decreto que facultaba al poder ejecutivo, es decir a Somoza, a incautar la maquinaria con que se editaban los periódicos, por violaciones cuya naturaleza él mismo fijaba (Amador, 2008:161). Esta decisión fue tomada seis días después de la gran manifestación que el Partido Conservador organizó el 22 de enero de 1967 y que acabó en tragedia. Este decreto estaba dirigido contra el diario La Prensa, pero su formulación también estaba encaminada a impedir la circulación de los periódicos obreros de la época. Con esta medida se evitaba la difusión de cualquier ideología diferente a la establecida, y es que el bipartidismo fue la norma política imperante en Nicaragua desde la independencia (1821) hasta el 19 de julio de 1979, año en el que es derrocada la dictadura somocista. Además, durante los últimos años de la dictadura, la Jefatura de Radio y TV impuso más de cien cierres y cuantiosas multas (Amador, 2008:161).

En 1977 -debido a la presión internacional- se levanta este estado de sitio, y el diario La Prensa empieza a publicar inmediatamente las noticias suprimidas por el 'Código Negro' para denunciar la corrupción de los funcionarios y la represión generalizada a la población, especialmente el campesinado, que ha sido la víctima más flagelada por la dictadura a través de 44 años de implantación del terror en las zonas rurales del país (Castillo, 1979). Como era de esperar, la combatividad de La Prensa tuvo dos efectos simultáneos: irritar al somocismo hasta niveles alienantes y estimular las movilizaciones populares contra la dictadura (Castillo, 1979).

El diario La Prensa realizó una fuerte oposición a la dictadura somocista, lo que provocó el asesinato de su director Pedro Joaquín Chamorro. El 10 de enero de 1978, Chamorro volvía de uno de sus frecuentes viajes a Estados Unidos, donde, entre otras cosas, había hablado ampliamente del "negocio de la sangre" . Cuando se dirigía a la redacción del medio de comunicación, un grupo de pistoleros lo acribillaron a balazos (Sánchez, 1979:135). Minutos después del asesinato ya había una multitud en las calles gritando: “iSomoza asesino!" y exigiendo una investigación (Sánchez, 1979:135). Al día siguiente, la Guardia Nacional se enfrentó a treinta mil manifestantes que protestaban por el crimen e incendiaron automóviles y seis edificios que alojaban 
empresas de los Somoza, entre ellas Plasmaféresis. Los motines continuaron durante los funerales de Chamorro y, por primera vez, se pidió la renuncia de Somoza. El dictador anunció que "con la ayuda de Estados Unidos gobernaré hasta 1981" (Sánchez, 1979:135).

Este hecho tuvo gran impacto, ya que nunca antes en las manifestaciones populares se habían escuchado consignas de apoyo al FSLN. También, los distintos medios informativos del país, encabezados por La Prensa, pasaron gradualmente a radicalizarse contra el régimen. Tras la muerte de Chamorro se produjo una fuerte indignación entre distintos sectores de la clase media y empresarial del país, quienes empezaron a apoyar sin tapujos a la revolución sandinista (Ramírez Soriano, 2016), una insurrección liderada por el FSLN.

Sin asumir necesariamente el proyecto revolucionario, La Prensa "logró ir difundiendo las luchas clandestinas, legales y semilegales que nuestro pueblo desarrollaba, para lanzarse de manera definitiva contra la dictadura" (Rotshchuh, 1986:32). En este sentido, Rotshchuh (1986) insiste en el aporte que este periódico "dio a la lucha cuando todos los medios de comunicación estaban censurados, estaban reprimidos, cuando el silencio amenazaba Nicaragua" (p.32). De hecho, cuando la Guardia Nacional destruyó la comunidad de Solentiname en 1977, Ernesto Cardenal escribió una 'Carta al pueblo de Nicaragua' que se publicó en este diario. Ahí explicaba que lo que había radicalizado a esa comunidad era el Evangelio, que comentaban cotidianamente en las misas (Cardenal, 2004:43).

El crimen de Pedro Joaquín Chamorro provocó que los periodistas se ne- garan a aceptar el sistema dictatorial establecido y optaran por organizarse asumiendo el mensaje del fallecido $y$, denominado por el gremio, "mártir de las libertades públicas” (Arellano, 2004:91). Debido a la presión existente crean una entidad que organiza a todos los periodistas del país, la Unión de Periodistas de Nicaragua (UPN), que dadas las condiciones de opresión impuestas por Somoza, apuesta por la libertad de prensa, bajo la presidencia de Danilo Aguirre Solís, quien ya para entonces se perfilaba como uno de los más destacables dirigentes del gremio (Arellano, 2008). Según el periodista Manuel Eugarrios, después de este asesinato, la crisis se volvió política y el periodismo se vinculó directamente a la lucha contra el somocismo: "La batalla de nuestro gremio no debía reducirse a Managua, sino que debíamos escalar a nivel nacional. Vanguardizamos la fundación de la UPN y logramos que fuera una realidad" (citado por Arellano, 2008).

Esta asociación se crea en la fecha de conmemoración del 'Día del Periodista' en Nicaragua, uno de marzo, (en este caso del año 1978), como organización gremial de carácter nacional. Se formó, como hemos dicho, tras el asesinato del director de La Prensa, después de que la Guardia arremetiera contra los monimboseños durante una misa celebrada en homenaje a su memoria, lo que se convirtió en el detonante de la famosa "rebelión de Monimbó" (Barreto, 1980). En definitiva, es importante destacar que a finales de enero y durante febrero de 1978, se muestra con claridad un ascenso de la lucha revolucionaria y en ello influyó tanto el asesinato de Pedro Joaquín como el papel ejercido por los medios de comunicación. 


\section{Medios de comunicación de masas sandinistas}

La primera experiencia de los sandinistas en lo que se refiere a prensa escrita había sido el control que lograron ejercer en la dirección de El Universitario, órgano de difusión del Centro Universitario de la Universidad Nacional Autónoma de Nicaragua (CUUN). En este medio de comunicación inició Pedro Joaquín Chamorro, el denominado "periodismo patriótico" con un artículo publicado en 1947. A través de éste exhortaba a la juventud nacional a convertir la fecha del asesinato del General Augusto César Sandino, (que hasta entonces se conmemoraba con un simple recordatorio), en un camino para alcanzar la "liberación de Nicaragua" (Briones citado en Amador, 2008:165).

Los dirigentes del FSLN llegaron a editar sus propios medios como El Sandinista, Trinchera, Rojo y Negro y Unidad Revolucionaria, además de su propia revista, Pensamiento Crítico. Mediante éstos pretendían difundir su doctrina revolucionaria, pero debido a la censura y a la persecución a la que estaban sometidos, ninguno tuvo una continuidad ni repercusión destacable. Lo que sí consiguieron los sandinistas fue colocarse en primera plana de la prensa internacional con el asalto a la casa de Chema Castillo en diciembre de 1974. Lograron así darse a conocer fuera de Nicaragua, ya que antes de esta acción mucha gente no tenía conocimiento de la situación del país centroamericano ni de la lucha del Frente Sandinista.

Aunque también esta actuación tuvo unas consecuencias muy negativas para quienes luchaban contra Somoza, ya que la represión se radicalizó aún más. Una de las primeras medidas que tomó el gobierno fue restablecer un rígido código de censura para la prensa, la radio y la televisión, que fue conocido como el 'Código Negro'. Controlado por el teniente coronel Alberto Luna, director de Radio y Televisión, la prensa quedó totalmente amordazada al mismo tiempo que se creaban tribunales militares para juzgar directamente cualquier brote de oposición al régimen (Sánchez, 1979:123).

A medida que los frentes de guerra del FSLN tomaban las ciudades, comenzaron a salir al aire algunas radioemisoras, difundiendo mensajes y partes de guerra de tropas victoriosas. Los nicaragüenses comenzaron a sintonizar en el dial nuevas emisoras que preludiaban la victoria final del pueblo en armas. Radio Insurrección, en Matagalpa; Radio Venceremos, en León; Radio Liberación, en Estela; Radio Revolución en Juigalpa; que venían a sumar sus voces a las transmisiones de la clandestina Radio Sandino. De hecho, fueron los miembros de la Unión de Periodistas de Nicaragua (UPN) quienes fundaron Radio Sandino en junio de 1978, una clandestina estación que jugó un rol esencial en la organización y preparación de combates que rompieron la dictadura (Amador, 2008:168). Un ejemplo es su importancia en el conocido popularmente como "El Repliegue", que tuvo lugar del 27 al 29 de junio de 1979. Hasta tal punto era importante que "en los cateos, los guardias se robaban los radios con onda corta para evitar que el pueblo escuchara Radio Sandino y Radio Reloj " (Barreto, 1980:18). Y es que, desde el 1de junio hasta el 19 de julio de 1979, Nicaragua vivió uno de los períodos más convulsos de su historia por el gran número de pérdidas humanas, la fuerte represión y la escasa información acerca de lo que ocurría. 
Los medios escritos fueron silenciados por la dictadura somocista y por las condiciones que imponía un paro general desde los primeros días de junio. Las radios corrieron la misma suerte y el diario La Prensa fue destruido por Somoza el día 11 de junio. En ese contexto, Radio Sandino se convirtió en una importante herramienta de comunicación para la guerrilla.

La radio sandinista era el medio para desmentir la información que daba la radio del dictador, ya que, según $\mathrm{Ba}-$ rreto (1980), estaba llevando a cabo "una guerra psicológica frente a la lucha heroica de los compañeros guerrilleros y del propio pueblo" (p.83). Y la misma función que Radio Sandino tiene en Nicaragua la tuvo diez años antes Radio Rebelde en Cuba, que comenzó a transmitir con cierta regularidad desde los territorios liberados en Sierra Maestra, el 24 de febrero de 1958, y jugó un papel fundamental en la difusión del mensaje de los guerrilleros que tenían que contrarrestar el poder de los medios de comunicación cubanos en manos de la dictadura (Pizarroso, 1993:444). El Comandante Humberto Ortega Saavedra destaca la importancia de Radio Sandino, e insiste en que "fue el principal elemento agitador para la insurrección y para la huelga. Sin una radio para orientar al movimiento de masas no habría habido triunfo revolucionario" (Mattelart, 1986:35).

En cuanto al cine, si partimos de que puede ser un aparato de transmisión ideológica, entendiendo el concepto ideología como "la representación de la relación imaginaria de los individuos con sus condiciones reales de existencia" (Althusser, 1971:139). Según Althusser, el Estado utiliza una serie de aparatos ideológicos para constituirse y afirmar sus mecanis- mos de poder, entre los cuales se encuentran la cultura (y dentro de esta categoría, el cine). En Nicaragua fueron los sandinistas, durante el proceso de lucha por la liberación y en su etapa gubernamental, quienes usaron el cine como medio de difusión (Amador, 2016:58). Se realizaron películas y, sobre todo, documentales, al mismo tiempo que la lucha se extendía por todo el país. Si analizamos la cinematografía nicaragüense de 1977 a 1979, llegamos a la conclusión de que aboga por una determinada representación de la nacionalidad y de la identidad, considerando el carácter simbólico de este tipo de nociones. Propone la eliminación de los paradigmas industriales extranjeros en la elaboración de sus argumentos y en sus novedades estéticas (Amador, 2014: 271272).

$\mathrm{Al}$ igual que en Cuba, la existencia de una población mayoritariamente analfabeta, -no sólo pobre-, sino también conformada por vastos sectores marginales, así como la inexistencia de antecedentes industriales en el cine antes de la Revolución -y contrariamente a los países de la región que habían desarrollado tempranamente sus cinematografías, como Argentina, Brasil y México- en Nicaragua son factores determinantes en la construcción de una industria del cine que pasa a ser concebida como una herramienta política fundamental (Velleggia, 225:2009). Dar presencia y visibilidad al proceso revolucionario en América y el resto del mundo fue uno de los principales objetivos de la política cinematográfica puesta en marcha por los institutos de cine nacional desde su fundación, inmediatamente después de haber triunfado la revolución (Velleggia, 225:2009).

En el Frente Sur Benjamín Zeledón fue donde surgió lo que posteriormente 
sería el Instituto Nicaragüense de Cine (Incine) -bajo el nombre de Brigada Cultural Leonel Rugama- para rendir homenaje al denominado por el FSLN "poeta militante", caído en combate contra la dictadura el 15 de enero de 1970. Así, apareció una cinematografía influenciada por la revolución (Amador, 2014). Muchos cineastas extranjeros participaron en ello, como el norteamericano John Sayles con 'Hombres armados' (1977), un "roadmovie" a medio camino entre la ficción y lo documental; 'Nicaragua, septiembre 1978', del holandés Frank Diamond; de los mexicanos Adrián Carrasco y Leo Gabriel, 'Nicaragua ¿Cuál es la consigna?' (1978/79); y Bertha Navarro con 'Nicaragua, los que harán la libertad' (1978). Cuatro meses antes de la victoria, el FSLN organizó una red de producción y distribución que debía filmar los combates, seleccionar las imágenes y distribuirlas fuera del país. Con ese sistema se rodaron casi treinta mil metros de película. Entre ellos se coprodujo, con Istofilme de Costa Rica, 'Nicaragua Patria Libre' (1978), dirigida por los costarricenses Antonio Yglesias y Víctor Vega y 'De la montaña al bunker' (1979), de Germán Téllez y Christine Piotter, que fue el documental que se elaboró junto a la columna Facundo Picado, hasta el asalto final al bunker de Somoza.

'La Ofensiva final' (1979) filmada por Pedro Talavera y Edgar Hernández, refleja perfectamente lo que fue el cine sandinista: una cinematografía que surgió en la acción y pretendió documentar el proceso de liberación. Considerada una movilización sin precedentes en la historia de Nicaragua desde la resistencia de Augusto César Sandino contra Estados Unidos a finales de los años veinte y principios de los treinta del siglo XX, difun- dirla llegó a ser una prioridad (Mattelart, 1986: 41).

\section{Oposición mediática a nivel internacional}

En cuanto a medios internacionales, uno de los testimonios más amplios y detallados que muestra los hechos concretos ocurridos en algunas de estas ciudades fue el publicado en Alemania por la prestigiosa revista Stern -que había enviado a Nicaragua corresponsales- donde se afirmó que mientras Somoza se encontraba encerrado en su búnker, unos siete mil quinientos soldados de la Guardia Nacional, encabezados por su hijo, Anastasio Somoza Portocarrero, habían salido a aplastar la sublevación llevando a cabo asesinatos en masa, "como bandas hitlerianas y de modo sólo comparable a lo ocurrido en Camboya" (citado en Ferrero, 2010:423).

Los periodistas temían que los combates pudieran extenderse al resto de Centroamérica porque era evidente que los sandinistas estaban apoyados por Costa Rica, Panamá y Venezuela, y el gobierno podría lograr el apoyo de los dictadores de Guatemala y El Salvador. Somoza, entre tanto, no dejaba de calificar los acontecimientos como "una conspiración comunista contra la democracia" (citado en Ferrero, 2010:423). Además de las declaraciones de estos reporteros, existe información obtenida de grabaciones de los sandinistas que interceptaban las conversaciones entre los guardias y sus mandos, que corroboran lo publicado por los profesionales de la comunicación de Stern (citado en Ferrero, 2010:423). De nuevo, observamos cómo los sandinistas se preocupan por denunciar "su sufrimiento y las injusticias a las que están 
sometidos" a través de los medios de comunicación.

La recuperación de la presidencia norteamericana por los demócratas en 1977, con Jimmy Carter, abrió paso a lo que al menos pareció una nueva expresión de la política de los Estados Unidos. El nuevo presidente inició una campaña en pro de los derechos humanos. Ese mismo año, Somoza Debayle sufrió una crisis cardiaca (Sánchez, 1979:129).

Las posibilidades de la muerte del dictador y el deseo de crear una nueva imagen de los "amigos" de Estados Unidos, motivaron a que el nuevo embajador de ese país en Nicaragua, el cubano-norteamericano Mauricio Solaun, llevara a Somoza la recomendación de que levantara la ley marcial y la censura de prensa. Como compensación, se le autorizó un nuevo crédito de armamentos. Aparentemente el gobierno norteamericano creía que Somoza podría controlar con facilidad a los guerrilleros sandinistas. Así, Estados Unidos tendrían en la mano las dos opciones de gobierno en Nicaragua: liberales y conservadores (Sánchez, 1979:131).

\section{Conclusión}

Los medios de comunicación de masas fueron determinantes para que el Frente Sandinista de Liberación Nacional
(FSLN) llegase al poder. No se puede obviar que éstos influyeron en el devenir de los acontecimientos y que, junto a otras formas de comunicación desarrolladas por los sandinistas, como las pintas, la poesía revolucionaria o la canción protesta, tuvieron gran influencia en la población. Especialmente significativo fue el asesinato del director de La Prensa, Pedro Joaquín Chamorro, que provocó la unión de todos los sectores de la sociedad contra la dictadura somocista y que trascendió las fronteras nacionales.

Los dirigentes sandinistas fueron conscientes, desde que comenzó a operar el movimiento guerrillero en los años sesenta, de la importancia de la comunicación para conseguir no sólo el apoyo de la población nicaragüense, sino también el de otros países, que acabó siendo fundamental para que se hiciesen con la victoria. Una vez en el poder, constituyeron el Departamento de Educación y Propaganda y, desde el Ministerio de Cultura, se promovió la poesía a través de la organización de talleres, se llevó a cabo una importante campaña de alfabetización y se creó un periódico oficial: Barricada, entre otras iniciativas.

En el caso del derrocamiento de la dictadura de los Somoza, podemos afirmar que los medios de comunicación de masas ejercieron como contrapoder y no fueron en absoluto neutrales, sino todo lo contrario. 


\section{BibLiOgRAFÍA}

Althusser, Louis (1971). Ideology and Ideological State Apparatuses. Lenin and Philosophy and Other Essays. Trans. Ben Brewster (pp.127-186). New York. Monthly Review Press

Amador, Belén (2016). "La influencia de la ideología en el Patrimonio Artístico a través del Instituto Nicaragüense de Cine". En Quiles, Fernando y Mejía, Karina (Eds.). Centroamérica Patrimonio Vivo (pp. 56-67). Sevilla. Acer - Vos. Patrimonio Cultural Iberoamericano.

(2014). "El Instituto Nicaragüense de Cine, un intento de rescatar y desarrollar la identidad nacional". En López, Rafael; Guasch, Yolanda y Romero, Guadalupe (Eds). América: cultura visual y relaciones artísticas, 269-276. (https://test.andaluciay america.com/wp-content/uploads/2018/06/America_Cultura_Visual.pdf).(Consulta 1801-2019).

(2008). "Nicaragua, periodismo preinsurreccional" (1977-1979). En Checa, Antonio y Ramírez, Maa del Mar(Eds). Visiones de América: comunicación, mujer e interculturalidad (pp. 159-179). La Coruña. Netbiblo.

Arellano, Jorge E. (2008). "Eugarrios, ejemplo de dignidad y valentía. El Nuevo Diario" (https://www.elnuevodiario.com.ni/opinion/35835-eugarrios-ejemplo-dignidad-valentia/) (consulta: 14-122018)

(2004). En Centro de Historia Municipal Alcaldía de Managua (Ed). Periodistas que iluminan nuestra historia (pp.35-38). Managua. Alcaldía de Managua.

Barreto, Pablo E. (1980). El Repliegue. De Managua a Masaya. México D. F. Editorial Cartago de México.

Bellido-Pérez, Elena (2018). "La instrumentalización propagandística del arte: El Expresionismo Abstracto patrocinado por la CIA". En Secretariado de Recursos Audiovisuales y Nuevas Tecnologías (Eds). Coleccionismo, mecenazgo y mercado artístico: su proyección en Europa y América (pp. 332-341).

Bordeira, Enrique; Laguna, Antonio y Martínez, Franscec A. (1998). Historia de la Comunicación Social. Madrid. Editorial Síntesis.

Calvo, Patricia (2010). "El proceso revolucionario cubano desde la óptica de la dimensión pública: el papel de los medios de comunicación". En Rey, Eduardo y Calvo, Patricia (Coords.). 200 Años de Iberoamérica 1810-2010:XIV Encuentro de Latinoamericanistas Españoles (pp. 1557-1576). Santiago de Compostela. Universidad de Santiago de Compostela.

Cardenal, Ernesto (2004). La Revolución Perdida. Madrid. Edit. Trotta.

Castells, Manuel (2008). Comunicación, poder y contrapoder en la sociedad red (I). Los medios y la política. Telos, 74, 13 24.

Castillo, D. (1979). "Perspectivas en la situación sociopolítica de Nicaragua". Nueva Sociedad, 42, 87-102

Chomsky, N y Herman, E. S. (1990). Los guardianes de la libertad. Barcelona, Grijalbo Mondadori.

De Mateo, Rosario (1998). Poder y modelo de comunicación en Nicaragua: de Somoza García al sandinismo (1988). Revista CIDOB d'Afers Internacionals, 14, 81-99. 
Fernández, Noel Padilla. (2016). "Pensar los medios: visibilizar la racionalidad como acción de resistencia comunicativa1. Armand Mattelart, crítica y pensamiento para la liberación en América Latina". Selección de textos publicados en la Revista Chasqui entre 1987 y 2011, 3, pp.111.

Ferrero, Ma Dolores (2010). La Nicaragua de los Somoza 1936-1979.Servicio de Publicaciones Universidad de Huelva. Huelva.

Hall, Stuart (1981)." La cultura, los medios de comunicación y el efecto ideológico". En James y otros (Comp.). Sociedad y comunicación de masas, pp.1-32. México D.F. Fondo de Cultura Económica.

Harnecker, Marta (1983). Pueblos en Armas. México D.F. Universidad Autónoma de Guerrero.

Isla, Luis (2002). "Desarrollo de la Comunicación Política". Razón y Palabra, (27).

Martí i Puig, Salvador (1997). La Revolución Enredada. Nicaragua 1977- 1996. Madrid. Los libros de la Catarata.

Martín Barbero, Jesús (2003). De los medios a las mediaciones. Comunicación, Cultura y Hegemonía. Bogotá. Unidad Editorial del Convenio Andrés Bello.

Mattelart, Armand (1986). Communicating in Popular Nicaragua. Bristol. SMC Typesseting.

Molina, Luis I. (2002). "Desarrollo de la comunicación política". Números. Recuperado de: Montenegro, Sofía (2007). Los medios de comunicación como actores políticos en Nicaragua. Los periodistas, los medios y el poder. Managua. Cinco.

Pizarroso, Alejandro (1993). Historia de la propaganda, notas para un estudio de la propaganda política y de guerra. Madrid. Ediciones de la Universidad Complutense de Madrid (EUDEMA).

Ramírez Soriano, Pau (2016). "Nicaragua: Sandinismo, revolución y religión". (http://diposit.ub.edu/dspace/bitstream/2445/103522/1/TFM_Pau_Ramirez.pdf).(Consultado. 30-12-2018)

Rothschuh, Guillermo (1986). Comunicación, la cuerda floja. Managua. Editorial Tierra Arada.

Sánchez, Mayo A. (1979). Nicaragua Año Cero. La caída de la dinastía Somoza. México D. F. Editorial Diana.

Velleggia, Susana (2009). La máquina de la mirada. Los movimientos cinematográficos de ruptura y el cine político latinoamericano. Buenos Aires. Altamira.

Vera, Héctor (1998). Desafíos democráticos del periodismo Chileno. Santiago de Chile. Editorial Universidad de Santiago 